\title{
Higher, sweeter, heavier: Not necessarily healthier
}

\section{NATIONAL FAMILY HEALTH SURVEY-4}

The recently released results of India's National Family Health Survey-4 (NFHS4) ${ }^{[1]}$ provide an overview of the health of the nation. A comprehensive exercise conducted across all states and union territories; its well-planned methodology and well-executed implementation ensure accuracy of data. In recent years, NFHS has begun assessing indicators of metabolic and vascular health so as to determine the burden of noncommunicable disease (NCD) and their risk factors.

NFHS4 has reported, among other parameters, the prevalence of underweight, obesity, hypertension, and "high blood sugar" in all states and districts. Although the cutoffs chosen for some indices (such as body mass index $[\mathrm{BMI}]$ and plasma glucose) may differ from the ones generally accepted in modern endocrinology, the results provide an estimate of the burden of metabolic dysfunction. Similarly, though NFHS4 uses descriptors which are not entirely accurate (for example, "sugar" instead of "glucose"), this should not distract the reader from interpreting the data properly. NFHS4 also describes the prevalence of certain risk factors for NCD such as alcohol and tobacco use as well.

\section{THE HIGH-PRESSURE STATES}

Hypertension, defined by NFHS4 as a blood pressure systolic $>140 \mathrm{mmHg}$ and/or diastolic $>90 \mathrm{mmHg}$, is noted in $8.8 \%$ of adult Indian women and $13.6 \%$ of adult Indian men. The highest prevalence of high blood pressure is noted in women from Sikkim (16.5\%), Assam (16.0\%), Nagaland (16.0\%), Punjab (13.2\%), and Tripura $(12.6 \%)$. In men, the highest risk of hypertension is found in Andaman and Nicobar Islands (AN) (27.9\%), Sikkim (27.3\%), Himachal Pradesh (21.9\%), Punjab (21.8\%), and Arunachal Pradesh (21.6\%) [Tables 1 and 2].

The lowest prevalence of hypertension is noted among women of Bihar (5.9\%), Kerala (6.8\%), Rajasthan (6.9\%), Dadra and Nagar Haveli (7.4\%), and Daman and Diu $(7.4 \%)$. The healthiest states for men, with regard to blood pressure, are Delhi (4.2\%), Daman and Diu (7.6\%), Bihar (9.4\%), Kerala (9.5\%), and Lakshadweep (9.9\%).

\section{THE SWEET STATES}

Diabetes has become endemic to India ${ }^{[2]}$ and contributes to the huge burden of cardiovascular disease. NFHS4 takes "high sugar" to be above $140 \mathrm{mg} \%$, and its data can be considered to reflect the combined prevalence of prediabetes and diabetes. "High sugar" levels are found in $8.6 \%$ of women and $11.9 \%$ of men across India. The "sweetest" states for women are Lakshadweep (17.2\%), AN (14.5\%), Goa (14.1\%), Kerala (13.5\%), and Mizoram (12.5\%). In men, the highest prevalence of high blood sugar is in $\mathrm{AN}(26.0 \%)$, Goa (19.6\%), Kerala (19.4\%), Lakshadweep (19.0\%), West Bengal (17.3\%), and Odisha (16.5\%).

The least prevalence of high sugars is seen in the women of Rajasthan (4.7\%), Maharashtra (5.3\%), Bihar (6.1\%), Meghalaya (6.1\%), Haryana (6.6\%), and Arunachal Pradesh (6.6\%). Similar rankings for men are Rajasthan (8.1\%), Haryana (8.2\%), Maharashtra (8.4\%), Jammu and Kashmir (9.1\%), and Meghalaya (9.3\%).

\section{THE HEAVY STATES}

Obesity is said to be the mother of all metabolic dysfunction. ${ }^{[3]}$ Overall, $20.7 \%$ of Indian women and $18.6 \%$ of men are obese. Another $22.9 \%$ women and $20.2 \%$ men are underweight. This implies that $43.6 \%$ women and $38.8 \%$ men have abnormal BMI in India. The prevalence of women with a BMI $>25 \mathrm{~kg}^{-2}$ is highest in Chandigarh (41.5\%), Lakshadweep (41.4\%), NCT Delhi (34.9\%), Andhra Pradesh (33.2\%), and Punjab (31.3\%). In men, the heaviest states are AN (38.2\%), Puducherry (37.1\%), Sikkim (34.8\%), Andhra Pradesh (33.5\%), and Goa (32.6\%).

States with lowest prevalence of obesity are Jharkhand (10.3\%), Bihar (11.7\%), Chhattisgarh (11.9\%), Meghalaya (12.2\%), and Assam (13.2\%) for women and Meghalaya (10.1\%), Chhattisgarh (10.2\%), Madhya Pradesh (10.9\%), Jharkhand (11.1\%), and Bihar (12.6\%) for men.

When analyzed for the prevalence of underweight $\left(\right.$ BMI $\left.<18.5 \mathrm{~kg}^{-2}\right)$, concordant results are noted. The highest prevalence of underweight women is seen 
Kalra, et al.: The health of the nation: National family health data from India
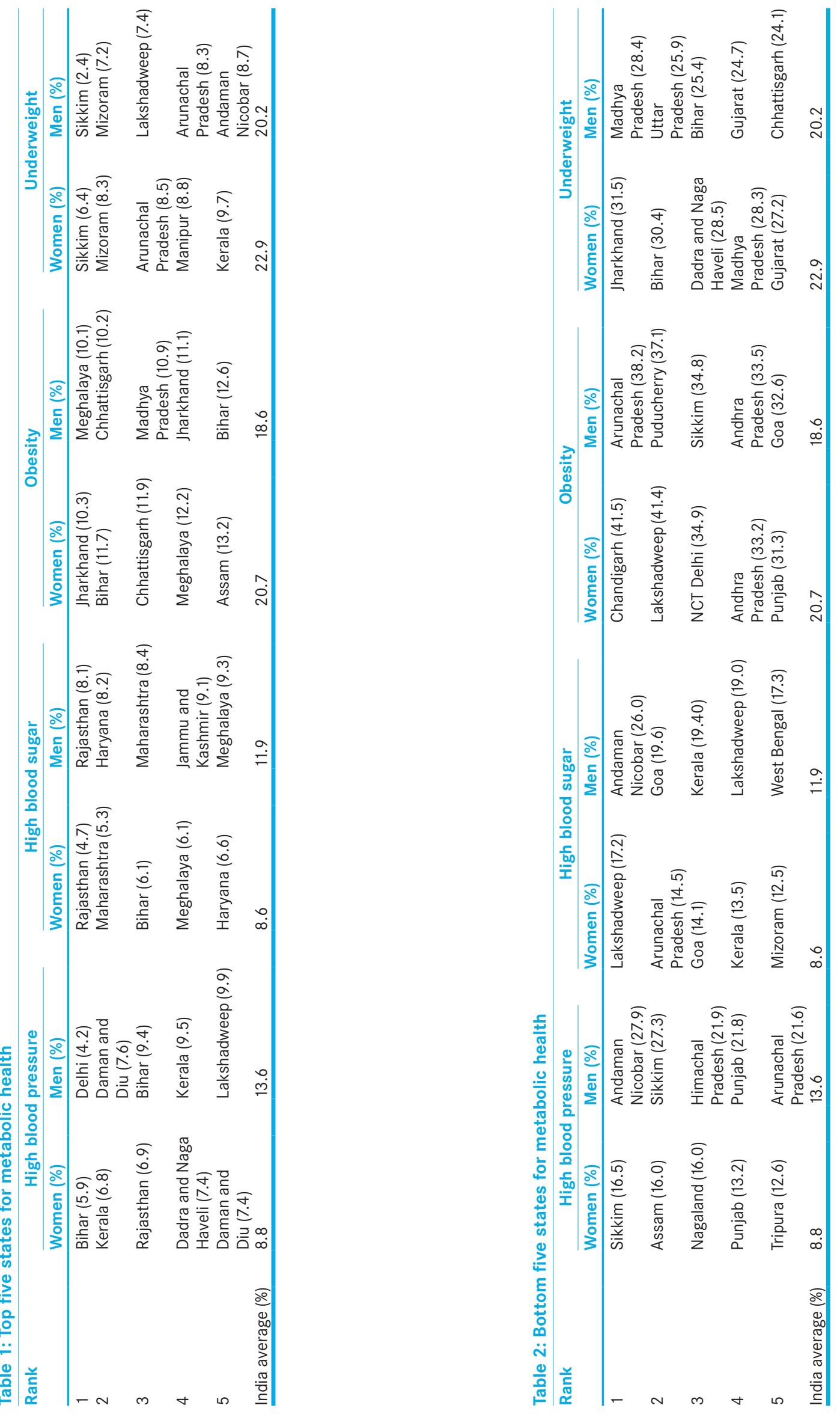
in Jharkhand (31.5\%), Bihar (30.4\%), Dadra and Nagar Haveli (28.5\%), Madhya Pradesh (28.3\%), and Gujarat $(27.2 \%)$. The maximum proportion of underweight men is in Madhya Pradesh (28.4\%), Uttar Pradesh (25.9\%), Bihar (25.4\%), Gujarat (24.7\%), and Chhattisgarh (24.1\%).

Underweight is least common in women of Sikkim (6.4\%), Mizoram (8.3\%), Arunachal Pradesh (8.5\%), Manipur $(8.8 \%)$, and Kerala $(9.7 \%)$. In men, the least underweight states are Sikkim (2.4\%), Mizoram (7.2\%), Lakshadweep (7.4\%), Arunachal Pradesh (8.3\%), and AN (8.7\%).

\section{ANALYSIS}

Certain facts are clear from the NFHS4 data. India faces a heavy burden of high blood pressure, uncontrolled glycemia, and obesity. At the same time, it still has to tackle adult undernutrition. The various states of India are heterogeneous in their genotype and lifestyle, and this is evident in their phenotype and health patterns. High blood pressure is most prevalent in the Northeast and the Northwest Himachal Pradesh and Punjab. This may be due to dietary habits such as high intake of salt. The inclusion of Delhi and Kerala on the list of states with least prevalence of high blood pressure is an anomaly which needs to be explored in NFHS5.

"High blood sugar," as measured in NFHS4, cannot be taken to reflect the actual prevalence of diabetes. However, it is clear that smaller states, such as Lakshadweep, AN, Goa, Mizoram, and Kerala, have the highest prevalence of impaired glucose tolerance. This may be due to rapid development, which brings with it urbanization and change of lifestyle.

Obesity, too, is relatively more common in the smaller states and union territories. Punjab, which had the distinction of being the heaviest state of India, has been relegated to $5^{\text {th }}$ place in women and $10^{\text {th }}$ in men. Its capital Chandigarh, however, ranks heaviest in the female and $6^{\text {th }}$ heaviest in the male category. Viewed from the other sides of the spectrum, a different list of states emerges. States such as Bihar, Jharkhand, and Rajasthan rank among the healthiest with regard to blood pressure, blood sugar, and overweight.
Haryana is considered the sports nursery of the country and is expected to rank among the fittest. Careful analysis shows that Haryanvi women and men rank near median for the prevalence of obesity and hypertension. The state is listed toward the healthier end of the spectrum for "high blood sugar," and underweight prevalence.

The results of NFHS4 need to be analyzed carefully, with an understanding of the methodology used. NDHS4 is a population-based survey, which provides an idea of the state of the nation's health and helps in policy planning and decision-making.

Sanjay Kalra, Arun Kumar ${ }^{1}$

Department of Endocrinology, Bharti Hospital, Karnal, ${ }^{1}$ Department of Community Medicine, Shaheed Hasan Khan Mewati Government Medical College, Nalhar, Haryana, India

Address for correspondence: Dr. Sanjay Kalra, Department of Endocrinology, Bharti Hospital, Karnal, India. E-mail: brideknl@gmail.com

\section{REFERENCES}

1. Key Findings from NFHS-4. Available from: http://www.rchiips.org/ NFHS/factsheet_NFHS-4.shtml. [Last accessed on 2017 Apr 01].

2. Kalra S, Kumar A, Jarhyan P, Unnikrishnan AG. Endemic or epidemic? Measuring the endemicity index of diabetes. Indian J Endocrinol Metab 2015;19:5-7.

3. Jung RT. Obesity as a disease. Br Med Bull 1997;53:307-21.

This is an open access article distributed under the terms of the Creative Commons Attribution-NonCommercial-ShareAlike 3.0 License, which allows others to remix, tweak, and build upon the work non-commercially, as long as the author is credited and the new creations are licensed under the identical terms.

\begin{tabular}{|l|l|}
\hline \multicolumn{2}{|c|}{ Access this article online } \\
\hline Quick Response Code: & Website: \\
\hline & www.joshd.net \\
\cline { 2 - 2 } & DOI: \\
& 10.4103/joshd.J_Soc_Health_ \\
\hline
\end{tabular}

How to cite this article: Kalra S, Kumar A. Higher, sweeter, heavier: Not necessarily healthier. J Soc Health Diabetes 2017;5:63-5. 